\title{
The Evolution of Shallow Seismic Exploration Methods
}

\author{
Don W. Steeples, Chris M. Schmeissner, and Brian K. Macy \\ Department of Geology, University of Kansas
}

\begin{abstract}
Near-surface seismic methods have developed considerably and have been applied much more widely since the 1970 s. Improvements in instrumentation, along with cheaper computer power, have greatly affected the capabilities of these methods in recent years. Based on these new capabilities we offer suggestions for future research in and applications for shallow-seismic exploration methods. We present our recommendations in the context of significant developments in shallow-seismic techniques from the 1920s to the mid-1990s, concentrating on seismic reflection and, to a lesser degree, refraction and surface-wave studies. The recent advent of hardware capable of collecting as well as processing high-resolution, near-surface seismic data opens up new opportunities for three-component recording and multimode analysis.
\end{abstract}

\section{Introduction}

For over 70 years, oil companies have used seismic methods to search for underground energy resources. Conventional seismic methods rely almost exclusively upon the acoustical images of geologic layers produced by $P$-waves, which briefly compress but do not distort the media through which they pass. However, the capabilities of seismic methods involving target depths shallower than, say, $30 \mathrm{~m}$ can be extended by analyzing seismic wave types that are usually discarded during processing, analysis, and interpretation. Specifically, it is becoming feasible to examine the near-surface broadband seismic wavefield by using three vector components rather than one and multiple types (modes) of seismic waves rather than $P$-waves alone.

Typically, seismologists deal with three principal types of waves. These include $P$-waves, mentioned earlier, which travel fastest and arrive first on seismograms; $S$-waves, which briefly distort materials but do not compress them and usually travel less than $60 \%$ as fast as $P$-waves; and surface waves, which travel along the surface of the Earth and move about $90 \%$ as fast as $S$-waves. In the past, surface waves have for the most part been considered noise, i.e., interference, by prospectors for hydrocarbons, although surface waves were employed as a tool applicable to some engineering-geophysical studies in the $1980 \mathrm{~s}$.

Techniques for seismological exploration in the past normally have involved either reflection or refraction. In $P$ wave reflection studies, the signals of interest are underground sound echoes. Thus, conceptually, the $P$-wave reflections recorded on seismograms are identical to our aural perception of echoes. Refraction is not as easily understood heuristically as reflection, but the phenomenon can be exemplified by our visual perception of a rainbow, although rainbows fall within the scope of optical physics rather than acoustical physics. Refraction studies are rooted in variations in the shortest-time pathway from the source of the seismic energy to the geophone that receives it. These pathway variations are caused by differences in the propagation speed of seismic waves traversing various earth materials. Here again, $P$-waves compress but do not distort a medium as they traverse it.

When using a traditional approach, the $S$-waves and surface waves are either destroyed during data collection and processing, or they are ignored during the geologic interpretation phase of the project. Moreover, $P$-wave refraction surveys make use of only the first signal arrivals, which typically contain less than one percent of the information that appears on a seismogram, whereas the remainder is ignored.

Conventional deep-reflection surveys may use $P$-wave refraction information to help obtain static corrections, i.e., corrections applied to the data to compensate for the effects of variations in elevation, weathering, and other near-surface geological anomalies. But in both $P$-wave-refraction and -reflection surveying, any information that might be obtained from surface-wave data is eliminated during processing or ignored during interpretation. However, when reflection surveys are undertaken at depths shallower than $30 \mathrm{~m}$, the refraction data may contain redundant structural information that can increase the usefulness of and confidence in the reflection information, while surface waves may contain data that can also be used to further constrain near-surfacereflection and -refraction interpretations.

\section{Scientific background}

A short discussion of the concept of dynamic range may aid in understanding the development of shallow-reflection methods and possible future applications of near-surface seismic methods. For example, a seismograph with a large dynamic range is capable of recording small signals in the presence of large amounts of noise, and until the 1960s, recording was done by means of analog circuits having a dynamic range of only about $40 \mathrm{~dB}$, or about one part in 100 . 


\section{Journal of Environmental and Engineering Geophysics}

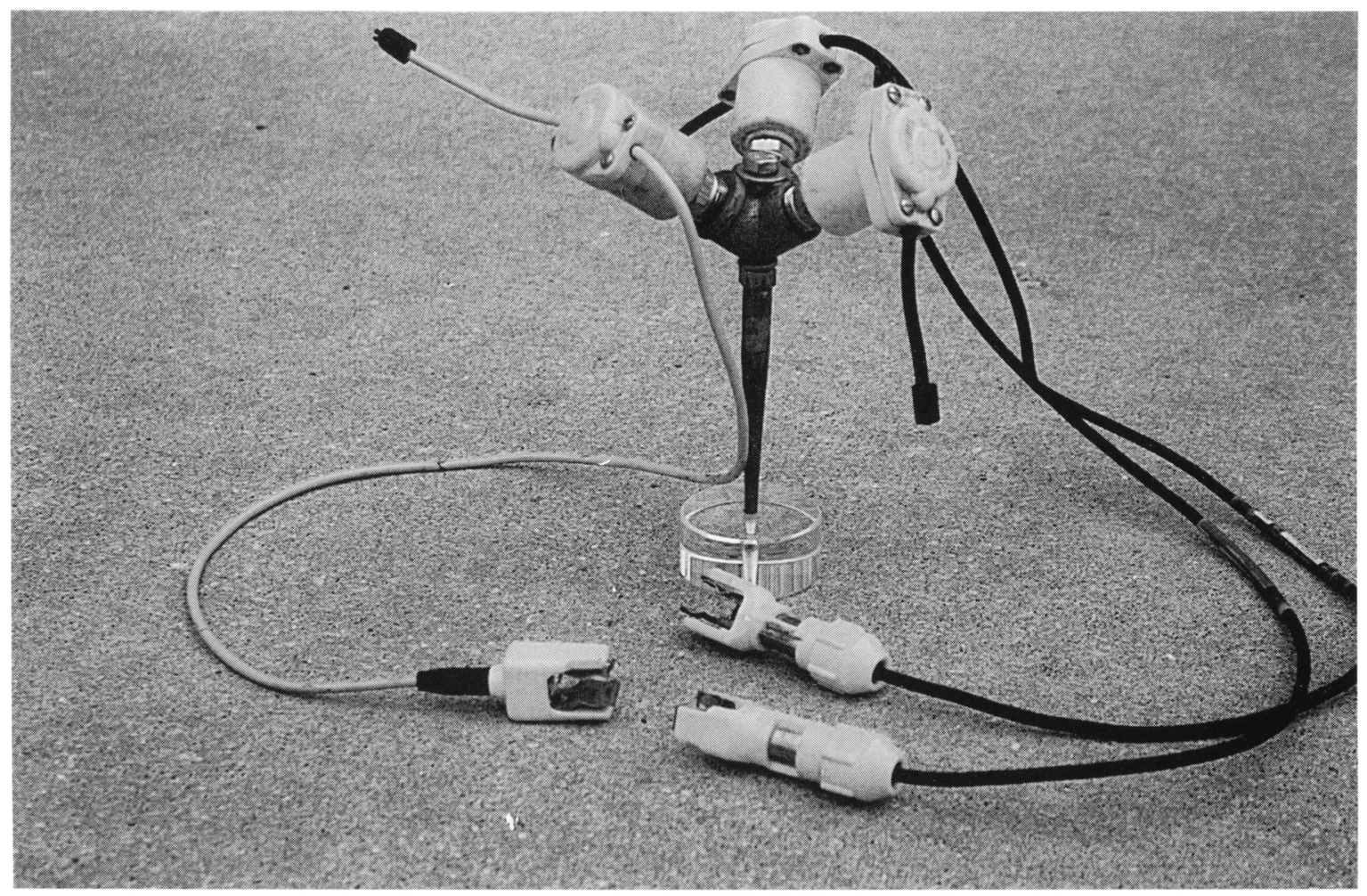

Figure 1. An orthogonal geophone system, commonly called a Galperin mount, showing three, 100-Hz vertical geophones mounted on a 90-degree, triple plumbing elbow with a single spike through the center of the elbow. In map view, the first geophone is set parallel to the shot line, the second 120 degrees clockwise from the first, and the third 120 degrees clockwise from the second. In the Galperin configuration, the three geophones are at an angle of $\alpha=54.7$ degrees to the vertical, or $\beta=35.3$ degrees to the horizontal.

With the appearance of digital circuits in the early 1960s, recording and extracting signals only $1 / 1000$ as great as the noise - for use in computer processing - became possible. However, as late as 1980, the cost of field equipment and the data-processing facilities needed to perform shallow-reflection surveys were in the range of one-million U. S. dollars. Consequently, these methods were used only when the potential financial rewards were great. Today, equipment capable of recording signals of the order of one-millionth of the intensity of the noise is readily available for a few tens of thousands of dollars.

Resolving power, or the information-carrying capacity of seismic data, is another important consideration and is directly related to frequency (Widess, 1973). In any shallow-reflection survey, lower limits on acceptable frequencies exist . This is a constraint born of the constructive and destructive interference between refractions and reflections, which is characteristic of the seismic waves that we see on the early portion of seismograms when near-surface reflectors are present. The importance of using high frequencies during shallow surveys was recognized fairly early in the history of seismic exploration, as noted by Clewell and Simon (1950): "It is concluded that the more profitable advances in the improvement of the resolving power of the reflection seis- mograph will result from techniques which shorten and simplify the input signal, rather than from efforts to widen the band of usable frequencies. The elimination of the nonlinear displacements in the vicinity of the shot point appears to be an obvious approach."

\section{Historical background}

Since 1980, significant strides have been made in nearsurface $P$-wave seismic-reflection surveying (Steeples and Knapp, 1982; Hunter et al., 1984), shallow-seismic refraction methods (Palmer, 1981; Lankston, 1990), and surfacewave techniques (Song et al., 1989; Stokoe et al., 1994). Nevertheless, we have found no evidence in the literature of pertinent, refereed articles reporting successful attempts to use all three types of data simultaneously to solve near-surface geological problems. Therefore, helping to fill this gap could be one of the long-term objectives of near-surface seismic research over the next five to ten years. Such an objective is feasible because of recent advances in field equipment and potential new approaches to data processing.

Historically, the earliest shallow seismic studies involved the use of refraction rather than reflection. However, a serious problem limited the applicability of refraction for use in seismic studies: seismic velocity within the Earth must 


\section{Steeples, Don W., et al.: The Evolution of Shallow Seismic Exploration Methods}

increase monotonically with depth for the theory of refraction to be applicable with accuracy, and this type of increase is often not the case in the real world.

Efforts by Evison (1952) in New Zealand in the early 1950 s are documented in the literature, but these reports mainly outlined the problems and frustrations of working in the shallow environment. Research by Pakiser and his colleagues at the U. S. Geological Survey appears to be the first published indication of the successful use of shallow reflection (Pakiser and Warrick, 1956).

One of the grand practitioners of engineering geophysics was Harold M. (Hal) Mooney, of the University of Minnesota, whose work spanned thirty years-from the 1950s to the early 1980s. He was also one of the founders of Bison Instruments, which has been among the principal vendors of seismographs and other near-surface geophysical exploration equipment beginning in the 1960s and continuing into the 1990s. Mooney produced practical field manuals that were widely distributed by Bison and that provided a sound basis for the successful use of shallow-reflection methods (Mooney, 1973). But the truly modern use of shallow-seismic reflection methods can be said to have begun with Schepers (1975), who produced some excellent shallow $P$-wave reflection results that were not fully appreciated in North America until the 1980s.

In fact, the use of shallow-reflection techniques was greatly expanded in the 1980s, and some of their limitations were also explored during that period. The optimum-window method (OWM; (Hunter et al., 1984) began to be used widely in engineering, environmental, and groundwater applications. Our own research focused on extending the limits of the resolution and applications of shallow-seismic reflection using common-depth-point (CDP) techniques and extensive routine digital processing (Steeples and Miller, 1990). Pullan and Hunter (1985) showed that substantial distortion of the reflected wavelet occurs at wide angles of incidence. Depending on the relative seismic velocity within the layers, this effect may become significant when the distance from the shot to the geophones exceeds the depth to the reflective interface.

In terms of specifics, our work in the late 1970s (Steeples, 1979) and early 1980s (Steeples and Knapp, 1982) was carried out with an A/D conversion of only 12 bits, using 12 channels, without floating-point (i.e., gain-ranging) amplifiers. Jim Hunter and his colleagues at the Geological Survey of Canada were using 8-bit and later 10-bit A/D conversion when they developed the OWM for shallow seismic reflection (Hunter et al., 1984). This method was designed to solve practical near-surface problems without the extensive and, at that time, expensive, use of digital signal processing. The limited dynamic range of equipment of this era made shallow-reflection surveying difficult and, most of the time, only one or two reflectors could be detected during a typical survey. The OWM specifically targeted the principal reflector of interest in terms of the selection of geophone offsets, pre-A/D low-cut filters, geophones, and seismic sources. At about that same time, Klaus Helbig and his students at the University of Utrecht in The Netherlands were making progress at a nearly ideal field testing site in the Dutch tidal flats (Doornenbal and Helbig, 1983).

By the late 1980 s, seismographs with 15 or 16 bits of $\mathrm{A} / \mathrm{D}$ conversion as well as floating-point amplifiers became available, and many had as many as 24 channels. The availability of a larger dynamic range and floating-point amplifiers had two important effects. First, the increased instantaneous dynamic range made expertise in the use of pre-A/D low-cut filters less critical. Secondly, the total dynamic range of systems with gain-ranging amplifiers allowed investigators to see reflections at depths of, say, $20 \mathrm{~m}$ as well as $200 \mathrm{~m}$ on the same seismograms. However, with only 24 traces of data, maintaining the coherency of the shallow reflections on individual shot records and at the same time occupying the longer offsets that provide needed velocity information

\section{Offset from Shot Point (m)}

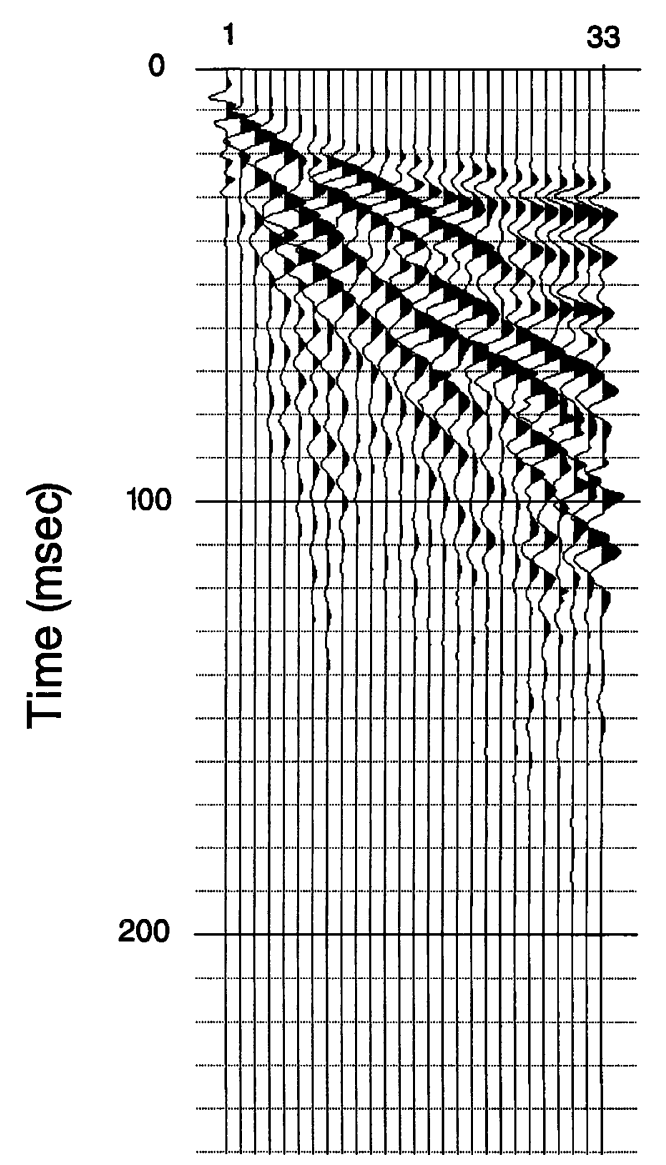

Figure 2. Single, vertical geophone field files from Sec. T.16 S. R.18 E. Location 330. 
Journal of Environmental and Engineering Geophysics
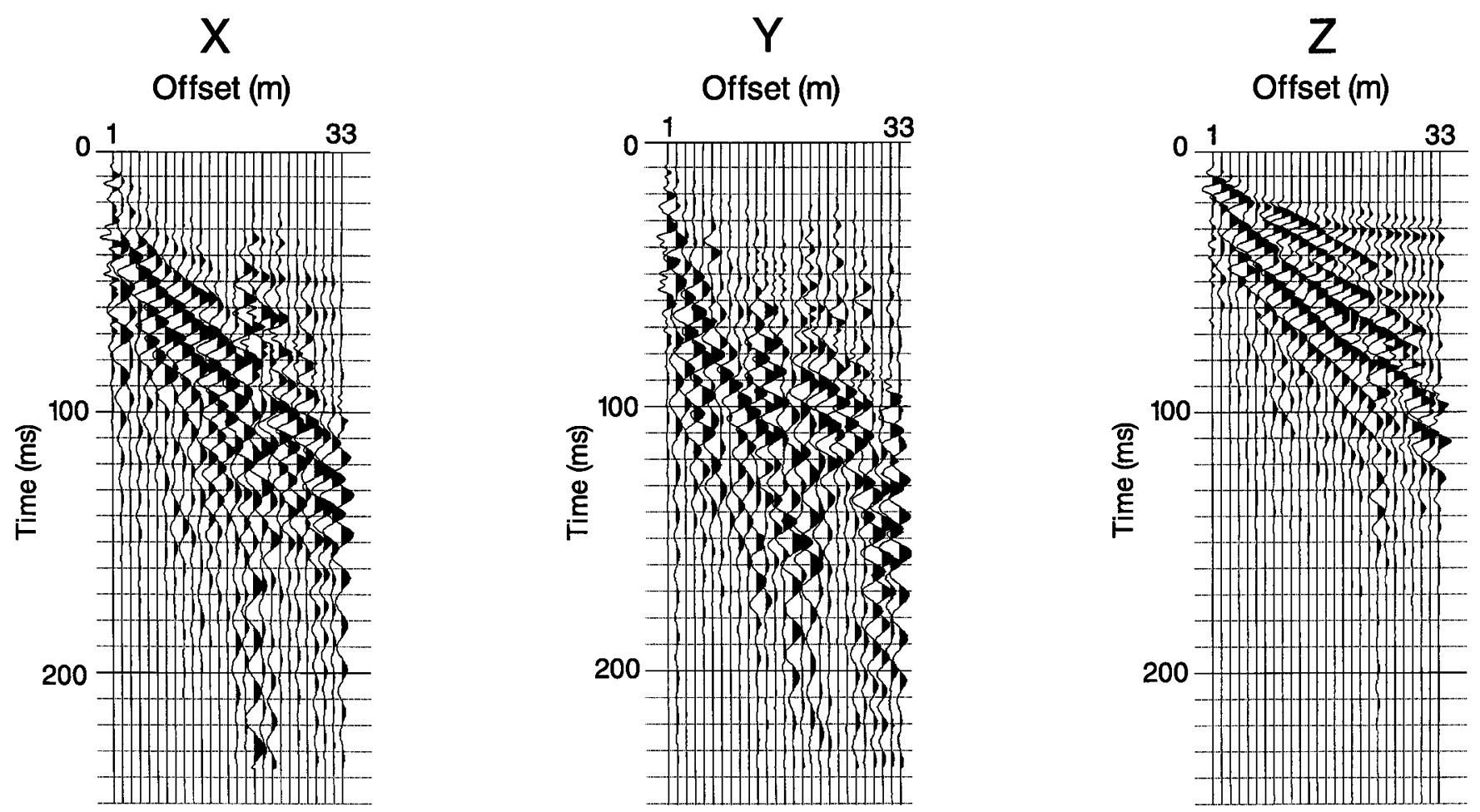

Figure 3. Rotated field files from Sec. T.16 S. R.18 E. Location 230.

about deeper reflecting layers was simply not possible. As an example, reliable common-depth-point (CDP) processing of reflections from a depth of $20 \mathrm{~m}$ usually requires 8 to 10 geophones at offsets less than $20 \mathrm{~m}$ from the shotpoint to avoid wide-angle distortion phenomena (Pullan and Hunter, 1985). On the other hand, obtaining velocity information from a reflection at $200 \mathrm{~m}$ requires that some geophones have offsets of about $200 \mathrm{~m}$ from the source (Knapp and Steeples, 1986). When the seismologist has only 24 channels with which to work, an essential contradiction develops when trying to set up field parameters that satisfy both needs.

The use of shallow $S$-wave reflections has not been widespread, but a few examples can be found in the literature (e.g., Hasbrouck and Padgett, 1982; Hasbrouck, 1991; Goforth and Hayward, 1992). The problem has been to try to separate the $S$-wave reflections from the surface waves that usually appear at the same time on the seismograms.

To analyze the uppermost layers of the earth, investigators have relied mainly on surface waves. The theoretical basis for this work was developed in the early 1960s (Jones, 1962), and some of the earliest practical work was done by the U. S. Army (Ballard, 1964). The civil engineering community (Stokoe et al., 1994) has been largely responsible for implementing surface-wave techniques.

In summary, the limited dynamic range of and small number of channels in engineering seismographs greatly hindered shallow-seismic reflection surveys until the 1980s. In addition, CDP data processing was prohibitively expensive until the late 1980s, when using personal computers to process information became feasible (Somanas et al., 1987). The limitations of near-surface seismology of that era included the ability to look at only one or two reflectors at once, record with only a single component (usually vertical), and analyze only a single phase or mode, usually $P$-wave.

\section{Adapting Seismic Technology to Routine, Near-Surface Use}

Recent advances in both instrumentation and personalcomputer technology promise expanded opportunities for the use of near-surface seismic-methods. Next, we consider some factors affecting the degree to which seismic methods may be applied in the future.

\section{Theoretical limitations}

Depending upon the problem at hand and the local geological or geotechnical situation, seismic methods may be hindered by a number of theoretical limitations. Perhaps the most important factor in reflection surveying is that there must be enough of an acoustical impedance contrast to generate a reflection. Moreover, the seismograph must have a dynamic range large enough to overcome groundroll and other forms of noise. High frequencies must be available to separate shallow reflections from refractions, while both high frequencies and wide bandwidths are necessary to achieve high resolution. Near-vertical incidence angles are required to 


\section{Steeples, Don W., et al.: The Evolution of Shallow Seismic Exploration Methods}

avoid wide-angle phase distortion (Pullan and Hunter, 1985). Ringing or reverberation of the near-surface layers is also a major geological limitation. And, at many sites characterized by environmental problems, the presence of cultural noise such as $60-\mathrm{Hz}$ powerlines, pavement, and excavated-fill materials prevents us from using reflection methods at all. For refractions to provide accurate depth information, the seismic velocity must monotonically increase with depth. By using the generalized reciprocal method of refraction analysis (Palmer, 1981), we can evaluate the error limits incurred while using refraction methods when velocity inversions are present.

\section{Data-collection cost factors}

The cost of reflection-data collection in terms of real dollars has fallen almost an order of magnitude over the past 15 years. In 1982, a good engineering seismograph with 24 channels and 12 bits of $\mathrm{A} / \mathrm{D}$ conversion cost about $\$ 6,000$ per channel. By 1995, we were looking at 48 to 120 channels with 18-24 bits of $\mathrm{A} / \mathrm{D}$ conversion costing about $\$ 1,000$ per channel (estimated in 1995 dollars, which have been devalued substantially by inflation since 1982). With equipment becoming more reliable, maintenance is no longer a major consideration. In addition, present-day equipment is light, rugged, and small enough to be returned to the factory by air express when necessary. Moreover, individual electronics boards can be shipped in the same way.

\section{Cost of energy per shotpoint}

It takes both money and time to introduce seismic energy into the ground; thus, seismic energy can best be applied by using high-output geophones and many recording channels. Geophone output can be increased by using highperformance magnets so that fewer geophones per string are needed to yield data of the same quality, which in turn means that fewer people are needed to accomplish the necessary field work.

Modern engineering seismographs can cycle at rates of at least six shots per minute, which is a factor at least two or three times faster than the seismographs of the early 1980s. As a result, we can now record and store digital near-surface seismic data and be ready to record again in less than 10 seconds. This has helped boost the rate of data collection in the field, which is now limited mainly by how long it takes to move and fire the energy source and to reposition the geophones and cables.

As the number of recording channels increases, finding Hunter's optimum window to obtain good reflection data becomes less critical. Smaller geophone group intervals are now possible, which helps minimize the trade-off between reflection coherency (obtained by using short geophone group intervals) and velocity information from the deeper layers (obtained with longer geophone offsets).

Shot- and geophone-group intervals are (or should be) proportional to reflector depth. Hence, because geophones cannot be planted without incurring costs, the expense of reflection surveying is partly an inverse function of depth, at least at depths ranging from $1 \mathrm{~m}$ to a few hundred meters.

As a result of the decreased seismograph cycling time between shots, several shots can be stacked vertically and the data stored individually to avoid, or to remove in processing, the effects of variable-source functions when successive shots are used at one location. Conversely, the key to productivity is to match the seismic source to the project so that only one shot, impact, or sweep is needed at each shotpoint. The minimum level of CDP-fold redundancy necessary to obtain interpretable sections should be obtained by field experimentation, because running the CDP-fold to greater numbers than necessary adds to the cost of both field work and data processing.

As data-collection speed has increased, the profile of the technical crew in the field also has changed somewhat. For example, more people are needed to move geophones and cables to keep pace with the seismograph, and the efficiency of the energy-source crew has become more important. The field crew often must work around environmental and other workplace constraints such as fences, buildings, or pipelines, plus constraints on the use of explosives and flammable materials. Furthermore, certain types of environmental, chemical constraints may prevent a crew from running a line at a critical location. These limitations increase the cost of operation and often decrease the geological quality of the results.

One key to cost containment is to run enough but not too many seismic lines. This kind of decision can be aided substantially by performing near-real-time processing using powerful on-site (or in-motel) personal computers.

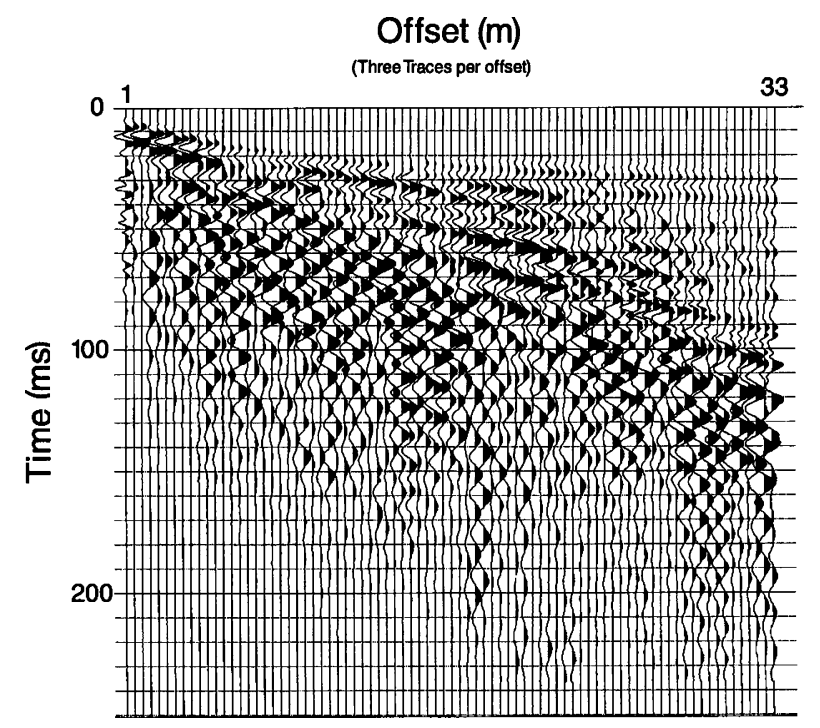

Figure 4. Single-shot field file configured for rolling Sec. T.16 S. R.18 E. Location 230. 
Journal of Environmental and Engineering Geophysics

\section{Data-processing cost factors}

Since about 1982, when the minimum cost of setting up a CDP-processing facility was between a quarter- and a half-million U. S. dollars, data-processing costs have dropped precipitously. By 1995 , the minimum cost for setting up a comparable facility had fallen to less than $\$ 5,000$.

The extent to which the successful processing of nearsurface seismic data is dependent upon the expertise of personnel must not be overlooked. Near-surface work requires more than simply scaling down deep-reflection processing methods. For example, when processing shallow data, factors such as air-blast and the muting of refractions are serious problems, whereas these constituents normally do not present difficulties during the processing of deep-reflection data.

Data quality, too, can have a strong influence on dataprocessing costs. The higher the quality of the data, the easier the processing. Because shallow targets require close geophone and shotpoint spacing, the number of traces per mile is an inverse function of target depth.

Often, the more advanced data-processing steps are either not needed or not appropriate for near-surface work. Black et al. (1994) have shown that migration commonly is not necessary when reflectors are within $10 \mathrm{~m}$ of the surface. Dip moveout (DMO) may or may not be suitable and, like migration, its use should be decided case by case. Deconvolution usually is not a pertinent processing method for near-surface reflection data, because one or more of the assumptions made for deconvolution may not be valid in the near-surface case. For example, statistically based deconvolution methods assume that subsurface reflections occur at a series of random times. However, we may have only one or two reflectors within the near-surface depth window of interest, and two reflections do not constitute a random series. Deconvolution techniques usually assume that the shape of the source wavelet does not change over time or in space, but these assumptions commonly do not hold true for near-surface seismic data.

\section{Three-Component Recording Methods}

High-dynamic-range and many-channeled seismographs offer more opportunities to extract information from the subsurface than ever before. For example, recording all three principal directional motions of the surface simultaneously (three-component seismic data) is now practical. The shallow environment is especially suitable for this type of recording because of the relatively broad bandwidth of the surface waves often seen on high-resolution reflection seismograms.

In three-component work, three geophones or transducers must be placed at a single-surface location: traditionally, one vertical geophone and two orthogonally-mounted horizontal geophones. An alternative three-component type

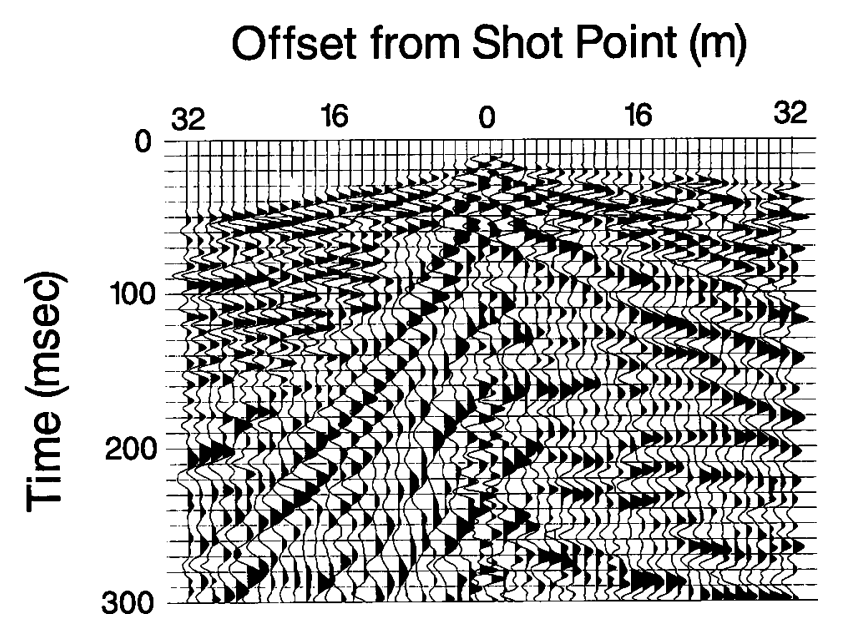

Figure 5. Field record taken from tests at the Bala kimberlite in Riley Co., Kansas. Notice the asymmetry about the shotpoint in the first-arrival energy and in the ground roll.

of mount was developed by Goff and O'Brien (1981) and is commonly called a Galperin mount, named for E. I. Galperin (1974). Figure 1 is a photo of an orthogonal geophone system showing three, $100-\mathrm{Hz}$ vertical geophones mounted on a 90-degree, triple-plumbing elbow with a single spike through the center of the elbow.

Two considerations are important when using a mount of this type. First, like the arrangement used by Goff and O'Brien, the geophones must be symmetrical to the vertical azimuth. This allows for gravity to have an equal effect on each of the geophones. The second consideration is frequency, or-even more important - the spring constant of the geophones.

Vertical geophones were designed to undergo vertical motion; therefore, tipping them away from the vertical may cause problems when the spring is not stiff enough to support the mass of the coil. As a result, geophones with too low a spring constant (i.e., low-frequency geophones) may not allow accurate motion along the design axis of the geophone when the geophone is oriented more than a few degrees away from vertical.

Using the field-recording method described above requires an extra step during processing. The data are recorded in a Cartesian-coordinate system that must be rotated to represent $x$-, $y$-, and $z$ - ground-motion velocities (the data may be rotated into any appropriate coordinate system). When the stress field of the subsurface is known, the user may wish to orient an axis relative to a given stress. However, when little is known about the test site, the most straightforward system is to set the $z$-axis positive in the upward direction, the $x$-axis along the shot line, and the $y$-axis perpendicular to the shot line. The choice of the $x$ - and $y$-axes is arbitrary, but it should produce a right-handed system.

A simple trigonometric transformation of the resulting digital data allows us to extract the principal-vector motions 


\section{Steeples, Don W., et al.: The Evolution of Shallow Seismic Exploration Methods}

(both of the horizontals and the vertical) from the data. The Galperin arrangement minimizes the static effect of gravity on recording and allows a more accurate analysis of the ground displacement we use to determine physical properties.

In map view, the first geophone in our field work is set parallel to the shot line, the second is 120 degrees clockwise from the first, and the third is 120 degrees clockwise from the second, or 120 degrees counterclockwise from the first. The first, second, and third geophones are labeled $G, G$, and $G$, respectively. The $x$-axis is parallel to the shot line, the $y$-âxis is perpendicular to the shot line, and the $z$-axis is pointing upward to form a right-handed coordinate system. The projection of the $G$ geophone into the $x-y$ plane is 30 degrees clockwise from the negative $y$-axis, and the projection of the $G$ geophone into the $x-y$ plane is 30 degrees counterclockwise $e^{c}$ from the positive $y$-axis. This 30 -degree angle is defined as $\gamma$.

In the Galperin configuration, the three positive geophones are at an angle of $\alpha=54.7$ degrees to the vertical, or $\beta=35.3$ degrees to the horizontal. The $G, G$, and $G$ geophones can be broken down into $x$-, $y$-, and $z^{a}$-components as follows:

$$
\begin{aligned}
& G_{a}=\hat{\boldsymbol{x}} G_{a x}+\hat{\boldsymbol{y}} G_{a y}+\hat{z} G_{a z} \\
& G_{b}=\hat{\boldsymbol{x}} G_{b x}+\hat{\boldsymbol{y}} G_{b y}+\hat{z} G_{b z} \\
& G_{c}=\hat{\boldsymbol{x}} G_{c x}+\hat{\boldsymbol{y}} G_{c y}+\hat{z} G_{c z} .
\end{aligned}
$$

Relating these to the $\beta$ and $\gamma$,

$$
\begin{aligned}
& \boldsymbol{G}_{a}=\hat{\boldsymbol{x}} G_{a} \cos \beta+\hat{\boldsymbol{y}} 0+\hat{z} G_{a} \sin \beta \\
& \boldsymbol{G}_{b}=-\hat{\boldsymbol{x}} G_{b} \cos \beta \sin \gamma-\hat{\boldsymbol{y}} G_{b} \cos \beta \cos \gamma+\hat{z} G_{b} \sin \beta \\
& \boldsymbol{G}_{c}=-\hat{\boldsymbol{x}} G_{c} \cos \beta \sin \gamma+\hat{\boldsymbol{y}} G_{c} \cos \beta \cos \gamma+\hat{z} G_{c} \sin \beta .
\end{aligned}
$$

Grouping $G_{a}, G_{b}$, and $G_{c}$ into $x$-, $y$-, and $z$-components:

$$
\begin{aligned}
& R_{x}=G_{a} \cos \beta-G_{b} \cos \beta \sin \gamma-G_{c} \cos \beta \sin \gamma \\
& R_{y}=\left(G_{c}-G_{b}\right) \cos \beta \cos \gamma \\
& R_{z}=\left(G_{a}+G_{b}+G_{c}\right) \sin \beta .
\end{aligned}
$$

The $R, R$, and $R$ components completely describe the ground motion in the $x-y-z$ Cartesian-coordinate system. After the data are rotated, three separate data sets exist $(x, y$, and $z$ ), and each can be processed accordingly.

The acquisition and processing of multicomponent data may require special considerations. From our discussion of rotation, we see that vector fractions of data from three recording channels are required to create a single-component trace. Therefore, the loss of a single channel destroys our ability to use the other two channels of the same geophone location. Because a given geophone requires three channels per location, the horizontal-offset distance for which data can be recorded per shot is reduced by a factor of three as compared to single-component recording, provided the geophone interval is constant. Thus, many recording channels are required. When we try to spread the distance between geophones to maintain a large range of offsets, spatial aliasing may become a factor. This problem must be given some attention, as we are now considering not only $P$-waves, but waves with much slower velocities (i.e., Rayleigh and Love waves) and shorter wavelengths.

\section{Seismic data from Franklin County, Kansas}

Examples of data taken with the three-component geophones and with regular, vertical, $100-\mathrm{Hz}$ geophones are shown in figs. 2, 3, and 4. Because the source (an 8-gauge Betsy Seisgun) and receiver locations are the same, a direct comparison can be made. In fact, $100-\mathrm{Hz}$, vertical geophones, which have relatively stiff internal springs, were used to construct the $100-\mathrm{Hz}$, three-component geophones shown in fig. 1 .

Figure 2 shows 27 channels of vertically mounted, single-geophone data using a Betsy Seisgun as a source, with a geophone interval of $4 \mathrm{ft}$. and a minimum offset of $4 \mathrm{ft}$. Figure 3 shows the $x$-, $y$-, and $z$-components for a field file at the same location as that of the data presented in fig. 2. The data were taken using a 24-bit Bison Model 24096 seismograph.

A 192-Hz, low-cut analog filter was applied before A/ $\mathrm{D}$ conversion. The rotation method discussed earlier was used to reduce the data. Comparing the $z$-component in fig. 3 and the field file in fig. 2 shows excellent agreement for a reflection at $55 \mathrm{~ms}$, for the refracted waves and for the groundroll portion of the record.

When performing seismic surveys over large distances, rolling along the seismic line is the most common technique. When doing this, the geophones at a given location must be

\section{Offset from Shot Point (m)}

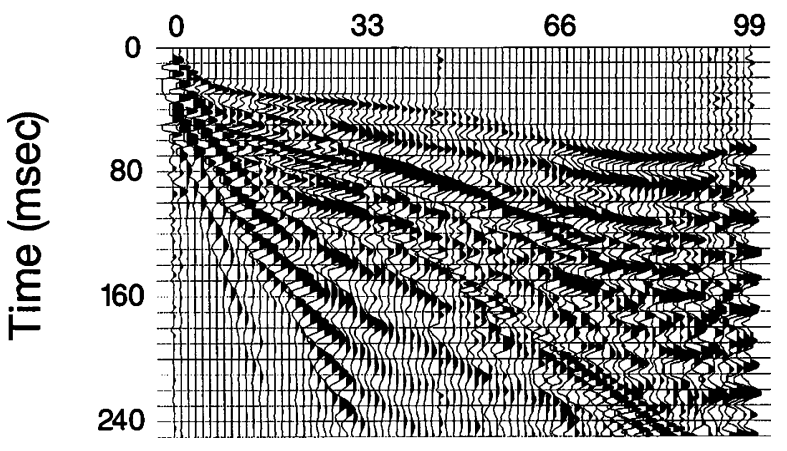

Figure 6. Field record taken from tests at the Bala kimberlite in Riley Co., Kansas. Notice that the first-arrival energy arrives at a time independent of distance from shot to receiver (i.e., infinite apparent velocity) at distances from about $70 \mathrm{~m}$ to $90 \mathrm{~m}$ from the shotpoint. 


\section{Journal of Environmental and Engineering Geophysics}
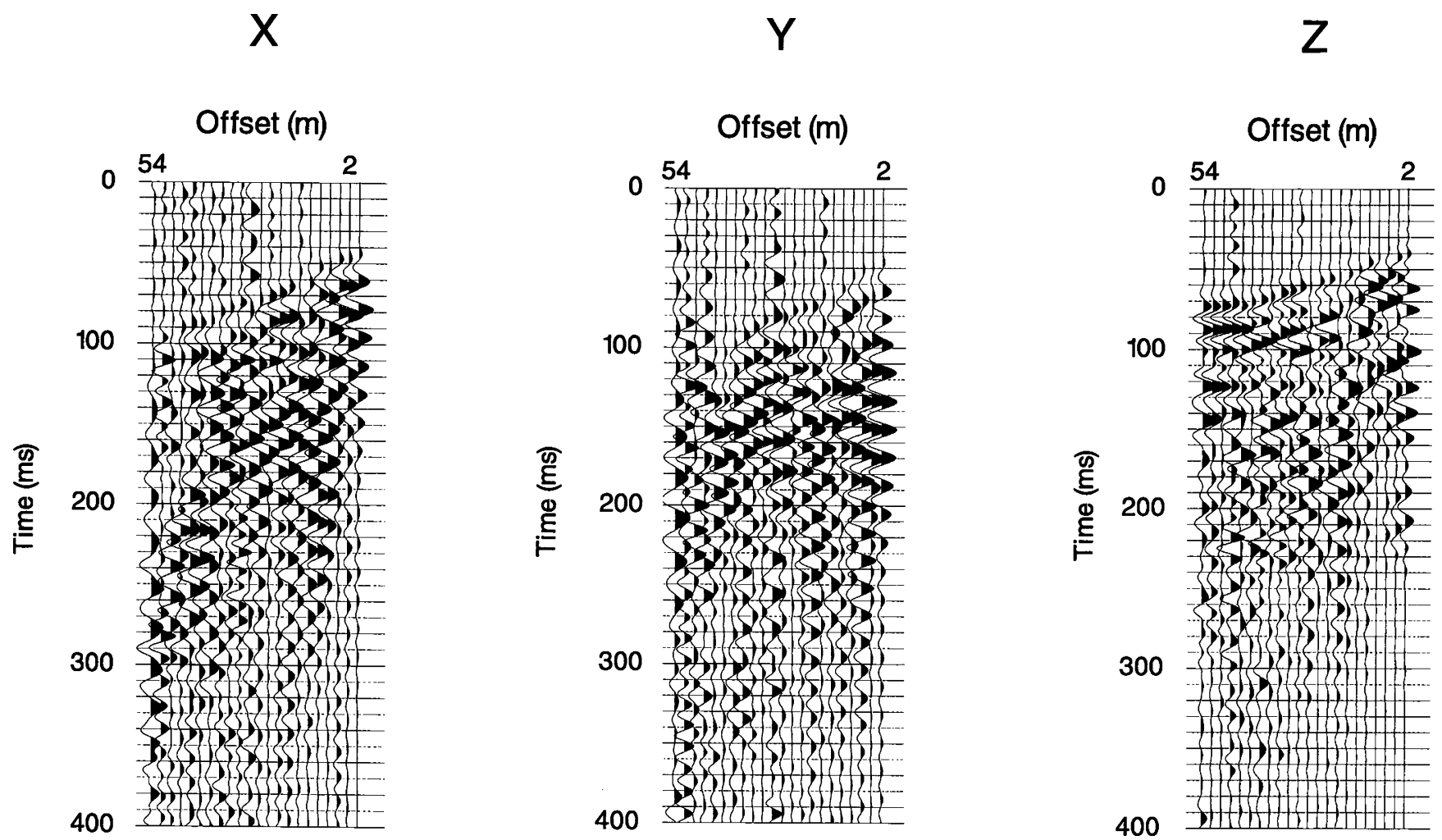

Figure 7. Rotated field files from the Bala kimberlite, Riley Co., Kansas.

connected sequentially along the line. Figure 4 shows a resultant three-component field file set up for rolling. Rotating the data file yields the components presented in fig. 3 . Rotated field-file data allow us to make interpretations in the field. However, if the data are not rotated first, interpretations may become difficult if not impossible when setting up for rolling. Figure 4 shows that, although refractions can be seen in the raw, unrotated data, reflection data may not be evident until rotation is performed.

Near-surface seismic complexity at the Bala kimberlite, Riley County, Kansas

Under certain conditions, a seismic wavefield can be generated in which all phases have energy well above 100 $\mathrm{Hz}$, thus allowing high-resolution analysis of the near-surface engineering properties (Song et al., 1989). In the summer of 1994, we recorded near-surface seismic data sets containing multiple modes of seismic information at our Bala kimberlite test site in Riley County, Kansas. This data set shows energy above $100 \mathrm{~Hz}$ in several modes (see figs. 5 and $6)$. These modes include $P$-wave reflection, $P$-wave refraction, $S$-wave, and surface-wave information, all of which give us information about the near-surface geology at that site-a geologically complex location subjected to violent intrusive igneous activity about 100 million years ago. The data could be analyzed by traditional means for each of the modes mentioned, and forward models could be constructed to satisfy the constraints set by each mode. However, if the modes were to present contradictions in geological constraints, no standard means of weighting the relative value or validity of each mode would be available to us at the present time.

Sample data from the Bala kimberlite site are shown in fig 6. Here we see an example of refracted first arrivals that have an apparent velocity greater than infinity. We first noted this phenomenon while using an 8-channel seismograph in the late 1970 s at this particular site, but when the data were shown at that time to a prominent seismologist for comment, his analysis was that we did not know where our geophones were during the recording, which was clearly not the case.

We returned to the site with a 96-channel seismograph and the intent of documenting this phenomenon more fully. In fig. 6, note the zone about 20 feet long on the ground where the first-arrival signals appear to arrive earlier as distance from the source increases. We have noticed this phenomenon at other sites as well but have found that geophone intervals of a few feet are necessary before the phenomenon is discernible. In this case, we believe that a high-velocity limestone has been deformed or possibly overturned and that the seismic energy is able to reach the geophones more quickly via the limestone than when it follows the shorter paths in the much slower near-surface materials. This phenomenon most likely would not be seen with the much larger geophone intervals commonly used for deeper surveys.

Where geological layering is homogeneous and flat- 


\section{Steeples, Don W., et al.: The Evolution of Shallow Seismic Exploration Methods}

lying, the first-arrival energy is symmetric about the shotpoint. However, our data set (fig. 5) shows asymmetrical first-arrival energy, which tells us about dip, structure, inhomogeneity, or some combination of these effects in the near-surface geology. In addition, in data displays not shown here, this asymmetry changes position from one side of the shotpoint to the other as the seismic source is moved along the line of receivers. We believe that this indicates the presence of significant geologic boundaries in the subsurface. These boundaries should also be recorded by other seismic modes in the data set, and data from multiple modes could help constrain the physical aspects of the boundaries. However, if we use reflection data alone, this information will be discarded.

Our conclusion is that none of the commonly used seismic methods tells the whole story. Consequently, research opportunities to develop methods incorporating multiple seismic modes simultaneously have expanded. For example, the use of a joint multimode inversion process might be one approach.

Figures 5, 6, and 7 display two data sets recorded at the same general locations at Bala, using the same source. However, fig. 7 presents the three-component data recorded using geophone spacing twice that of the vertical-geophone data shown in figs. 5 and 6.

As before, the $z$-component and the vertical data show the same characteristics.

The $x$-component in figs. 7 demonstrates the problem of spatial aliasing, even though the geophone interval is only eight feet. Note that the true seismic events run from right to left on the diagonal. However, in the $x$-component, spatially aliased - and therefore invalid - seismic events can be seen moving left to right on the diagonal. Again, this confirms the importance of rotating the data in the field to identify potential problems.

With the availability of seismographs having a large number of channels, we are convinced that the opportunities presented by three-component data outweigh the current shortcomings in data acquisition and that, as research in the area continues and more specific information can be readily obtained by multimode seismic analysis of the shallow subsurface, three-component techniques are likely to proliferate.

\section{Significance of Near-Surface Seismic Methods}

Geophysical methods can often be more cost-effective than test drilling, so a hundred years from now civil engineering and environmental seismic studies of the near surface will no doubt include three components, three dimensions, and full-elastic, i.e., multimode, inverse solution of the wave equation. Because the wave equation relates the spatial and time dependence of an elastic disturbance that propagates as several types of seismic waves, it can be used to identify the mechanical and hydrologic properties of soils, aquifers, and other significant near-surface layers. Thus, we recommend that the kinds of new opportunities discussed here be explored, using three-component recording and multimode analysis.

\section{References}

Ballard, R. F., Jr., 1964, Determination of soil moduli at depth by in situ vibratory techniques: Miscellaneous paper \# 4-691, U. S. Army Engineer Waterways Experiment Station, Vicksburg, Mississippi, 9 pp.

Black, R., Steeples, D. W., and Miller, R. D., 1994, Migration of shallow reflection data: Geophysics, 59, 402-410.

Clewell, D. H., and Simon, R. F., 1950, Seismic wave propagation: Geophysics, 15, 50-60.

Doornenbal, J. C., and Helbig, K., 1983, High-resolution reflection seismics on a tidal flat in the Dutch Delta-Acquisition, processing and interpretation: First Break, 1, no. 5, 9-20.

Evison, F. F., 1952, The inadequacy of the standard seismic techniques for shallow surveying: Geophysics, 17, 867-875.

Galperin, E. I., 1974, Vertical seismic profiling: Soc. Expl. Geophys. Special Pub., Tulsa.

Goff, D. D., and O'Brien, J. T., 1981, U. S. Patent No. 4,300,220, issued $11 / 10 / 81$.

Goforth, T., and Hayward, C., 1992, Seismic reflection investigations of a bedrock surface buried under alluvium: Geophysics, 57, 1217-1227.

Hasbrouck, W. P., 1991, Four shallow-depth, shear-wave feasibility studies: Geophysics, 56, 1875-1885.

Hasbrouck, W. P., and Padget, N., 1982, Use of shear wave seismics in evaluation of strippable coal resources: Utah Geological and Mineral Survey Bull._118, 203-210.

Hunter, J. A., Pullan, S. E., Burns, R. A., Gagne, R. M., and Good, R. S., 1984, Shallow seismic reflection mapping of the overburden-bedrock interface with the engineering seismographsome simple techniques: Geophysics, 49, 1381-1385.

Jones, R., 1962, Surface wave technique for measuring the elastic properties and thickness of roads: Theoretical development: British Journal of Applied Physics, 13, 21-29.

Knapp, R. W., and Steeples, D.W., 1986, High-resolution common depth point seismic reflection profiling: field acquisition parameter design: Geophysics, 51, 283-294.

Lankston, R. W., 1990, High-resolution refraction seismic data acquisition and interpretation: in Geotechnical and environmental geophysics, 1, Review and Tutorial, Ward, S., Ed., Investigations in Geophysics No. 5, Soc. Expl. Geophys., 4574.

Mooney, H. M., 1973, Handbook of Engineering Geophysics: Bison Instruments Inc., Minneapolis.

Pakiser, L. C., and Warrick, R. E., 1956, A preliminary evaluation of the shallow reflection seismograph: Geophysics, 21, 388405.

Palmer, D., 1981, An introduction to generalized reciprocal method 
Journal of Environmental and Engineering Geophysics

of seismic refraction interpretation: Geophysics, 46, 15081518.

Pullan, S. E., and Hunter, J. A., 1985, Seismic model studies of the overburden-bedrock problem: Geophysics, 50, 1684-1688.

Schepers, R., 1975, A seismic reflection method for solving engineering problems: Geophysics, 41, 367-384.

Somanas, D., Bennett, B., and Chung, Y., 1987, Infield seismic CDP processing with a microcomputer: The Leading Edge, 6, 24-26.

Song, Y. Y., Castagna, J. C., Black, R. A., and Knapp, R. W., 1989, Sensitivity of near-surface shear-wave velocity determination from Rayleigh and Love waves: in 59th Ann. Internat. Mtg., Soc. Expl. Geophys., Expanded Abstracts, 509-512.

Steeples, D. W., 1979, A repeatable seismic energy source for shallow groundwater exploration [Abstract]: EOS Transactions of the American Geophysical Union, 60, 830.

Steeples, D. W., and Knapp, R. W., 1982, Reflections from 25 feet or less: in 59th Ann. Internat. Mtg., Soc. Expl. Geophys., Expanded Abstracts, 469-471.

Steeples, D. W., and Miller, R. D., 1990, Seismic-reflection methods applied to engineering, environmental, and groundwater problems: in Geotechnical and environmental geophysics, 1, Review and Tutorial, Ward, S., Ed., Investigations in Geophysics No. 5, Soc. Expl. Geophys., 1-30.

Stokoe, II, K. H., Wright, G. W., James, A. B., and Jose, M. R., 1994, Characterization of geotechnical sites by SASW method, in Woods, R. D., Ed., Geophysical characterization of Sites: ISSMFE Technical Committee \#10, Oxford Publishers, New Delhi.

Widess, M. B., 1973, How thin is a thin bed: Geophysics, 38, $1176-$ 1180 . 